\title{
Utilizing neural networks for image downscaling and water quality monitoring
}

\author{
R. S. Makar* (D) \\ Soils and Water Use Department, Agricultural and Biological Research Institute, National \\ Research Centre, Dokki, Cairo, Egypt \\ M. Faisal \\ Drainage Research Institute, National Water Research Center, Egypt \\ *Corresponding author. Email: randa_sgmm@yahoo.com
}

\section{Article Info}

https://doi.org/10.31018/

jans.v13i4.3146

Received: November 1, 2021

Revised: December 3, 2021

Accepted: December 5, 2021

\section{How to Cite}

Makar, R. S. and Faisal, M. (2021). Utilizing neural networks for image downscaling and water quality monitoring. Journal of Applied and Natural Science, 13(4), 1452 - 1461. https://doi.org/10.31018/jans.v13i4.3146

\section{Abstract}

Remotely sensed images are becoming highly required for various applications, especially those related to natural resource management. The Moderate Resolution Imaging Spectroradiometer (MODIS) data has the advantages of its high spectral and temporal resolutions but remains inadequate in providing the required high spatial resolution. On the other hand, Sentinet2 is more advantageous in spatial and temporal resolution but lacks a solid historical database. In this study, four MODIS bands in the visible and near-infrared spectral regions of the electromagnetic spectrum and their matching Sentinel-2 bands were used to monitor the turbidity in Lake Nasser, Egypt. The MODIS data were downscaled to Sentinel2, which enhanced its spatial resolution from 250 and $500 \mathrm{~m}$ to $10 \mathrm{~m}$. Furthermore, it provided a historical database that was used to monitor the changes in lake turbidity. Spatial approach based on neural networks was presented to downscale MODIS bands to the spatial resolution of the Sentinel-2 bands. The correlation coefficient between the predicted and actual images exceeded 0.70 for the four bands. Applying this approach, the downscaled MODIS images were developed and the neural networks were further employed to these images to develop a model for predicting the turbidity in the lake. The correlation coefficient between the predicted and actual measurements reached 0.83 . The study suggests neural networks as a comparatively simplified and accurate method for image downscaling compared to other methods. It also demonstrated the possibility of utilizing neural networks to accurately predict lake water quality parameters such as turbidity from remote sensing data compared to statistical methods.
\end{abstract}

Keywords: Image downscale, Lake turbidity, MODIS, Neural network, Sentinel-2

\section{INTRODUCTION}

Remote sensing offers the opportunity to monitor and manage natural resources at various temporal, spectral and spatial resolutions. It thus offers great potential for developing more effective management strategies (Kumar et al., 2015). In this aspect, water is among the natural resources that require frequent monitoring to better understand its use, particularly in regions where the amount of water is limited, such as in Egypt.

Lake turbidity is highly dynamic and its temporal variations have been attributed to factors such as algal blooms and the concentration and character of suspended sediments and dissolved organic matter etc. (Liu et al., 2007). Lake turbidity spatial variations are not easily revealed by in situ based measurement and are considered time-consuming and expensive and are usually confined to a few monitoring points measured a few times each year (Flores-Anderson et al., 2020).

Many studies have used data acquired by multispectral high spatial resolution sensors for lake water quality monitoring, such as Landsat (Guan, 2009; Abdullah, 2010; and Mohsen et al., 2021) and Sentinel-2 (Toming et al., 2016, Blix et al., 2018 and Brescianiet al., 2019). However, the temporal resolution of Landsat cannot capture the rapid changes that may occur within a lake. On the other hand, Sentinel-2was launched in June 2015 and therefore lacked the historical archive, which allows monitoring the changes occurring within the lakes over time. On the other hand, the MODIS data has been utilized in various lake water quality monitoring studies(Wu et al., 2009; McCullough et al., 2012and Avdanet al., 2019). Nevertheless, despite having a high temporal resolution that can rapidly catch the water quality changes, MODISlacks the spatial resolution required for such studies. 
In this aspect, downscaling has played an important role in remote sensing, and it allows prediction at a finer spatial resolution than that of the input imagery (Atkinson, 2013). Recently, downscaling using machine learning algorithms, such as artificial neural networks (ANN), has gained more recognition because of their fast operation and high computing precision (Li et al., 2019).

ANN imitate the physical process of learning in the human brain. It consists of artificial neurons that imitate the biological neurons and the synaptic connections among them, regulating them through problem-solving (Canzianiet al., 2008). These neurons are logically arranged in an input layer, an output layer, and one or more hidden layers. The input layer is the mean by which data are presented to the network, and the output layer holds the network's response to the input. The hidden layers enable these networks to represent and compute complicated associations between the inputs and outputs (Erzinet al., 2010).

The ANN is considered appropriate for dealing with a large set of variables and their nonlinearity is convenient for analyzing complex systems (Canzianiet al., 2008). Various studies have employed neural networks for downscaling image products such as water Chlorophyll (Fu et al., 2018 and Mohebzadeh and Lee, 2020); Land surface temperature (Li et al. 2019 and Yooet al., 2020); NDVI (Nomura and Oki, 2021) and soil moisture (Senanayakeaet al., 2019). Nevertheless, the studies that discuss the downscaling of the remote sensing reflectance data usually involving more complicated methods are as the smoothing filter-based intensity modulation technique (SFIM) (Santi, 2010), and the recently developed area-to-point regression kriging (ATPRK) approach (Wang et al., 2016), as well as the popular Spatial and Temporal Adaptive Reflectance Fusion Model (STARFM) (Cui et al., 2018).

This study proposes a method for spatial downscaling the MODIS reflection data of 250 and $500 \mathrm{~m}$ resolution to $10 \mathrm{~m}$ utilizing the neural networks and monitoring the changes in water quality (i.e. turbidity) in Lake Nasser, Egypt.

\section{MATERIALS AND METHODS}

\section{Study area}

Nasser Lake is an artificial basin that was formed due to the construction of Aswan High Dam (Fig. 1). The only source of its water is the River Nile inflow from the south. The flood season always takes place from the end of July to November (AbdEllah, 2020). Lake Nasser is about $35 \mathrm{~km}$ at its widest point with an average width of $12 \mathrm{~km}$ with a maximum water depth is $120 \mathrm{~m}$ near the Aswan High Dam (Salem, 2011). The lake is featured by numerous side extensions located on both sides, known as Khors (AbdEllah and El-Geziry, 2016).
The water levels in the lake vary from year to year, according to the coming flood, and from month to another, according to the discharge from the lake across the High Dam. This fluctuation of water level affects the water quality status of the lake and its Khors due to the change of their morphometric configuration (Salem, 2011).

\section{Remote sensing data}

Both MODIS and Sentinel-2 data were used in this study, and they were acquired free of charge via the internet (https://earthexplorer.usgs.gov). The data were processed using two sets of software. The remote sensing and GIS software included the QGIS version 3.16, while the ANN processing employed used the MATLAB software.

\section{MODIS data}

Aqua and Terra are two polar-orbiting satellites launched by the US National Aeronautics and Space Agency (NASA). The Terra spacecraft launched on December 18, 1999, and the Aqua spacecraft launched on May 4, 2002. Both Terra and Aqua satellites operate in near sun-synchronous polar orbits with a nominal orbit altitude of $705 \mathrm{~km}$. MODIS is carried on both satellites with 36 spectral bands and provide near-daily observations. Four bands were used in this study. Two bands were at $250 \mathrm{~m}$ spatial resolution, one in the red range and the other in the near-infrared. On the other hand, band three and four were available at $500 \mathrm{~m}$. Band 3 was in the blue range, while band 4 was in the green range (Moreno-Madrinanet al., 2010).

Terra MODIS data in the form of MOD09A1 and MOD09Q1 Version 6products were used. These products provided surface spectral reflectance of Terra MODIS corrected for atmospheric conditions. For each pixel, a value was selected from all the acquisitions within the 8-day composite period. The criteria for the pixel choice include cloud and solar zenith. When several acquisitions meet the criteria, the pixel with the minimum band 3 value is used. MOD09A 1 provides an estimate of the first seven reflectance MODIS bands at $500 \mathrm{~m}$, while MOD09Q1 provide spectral reflectance Bands 1 and 2 at $250 \mathrm{~m}$ (Vermote, $2015 \mathrm{a}$ and b). For each of the studied dates, the first two bands were of the MOD09Q1, $250 \mathrm{~m}$ data, while bands three and four were of the MOD09A1, $500 \mathrm{~m}$ data. Furthermore, the study area was covered by two MODIS images. Therefore, four images were downloaded for each date.

The MODIS products are distributed in the Hierarchical Data Format - Earth Observing System (HDF-EOS). The MODIS data were imported and converted into Tiff format using the QGIS's Semi-Automatic Classification Plug-in (SCP). For each date, the two images that covered the study area were mosiked using the same tool (Fig. 2). 


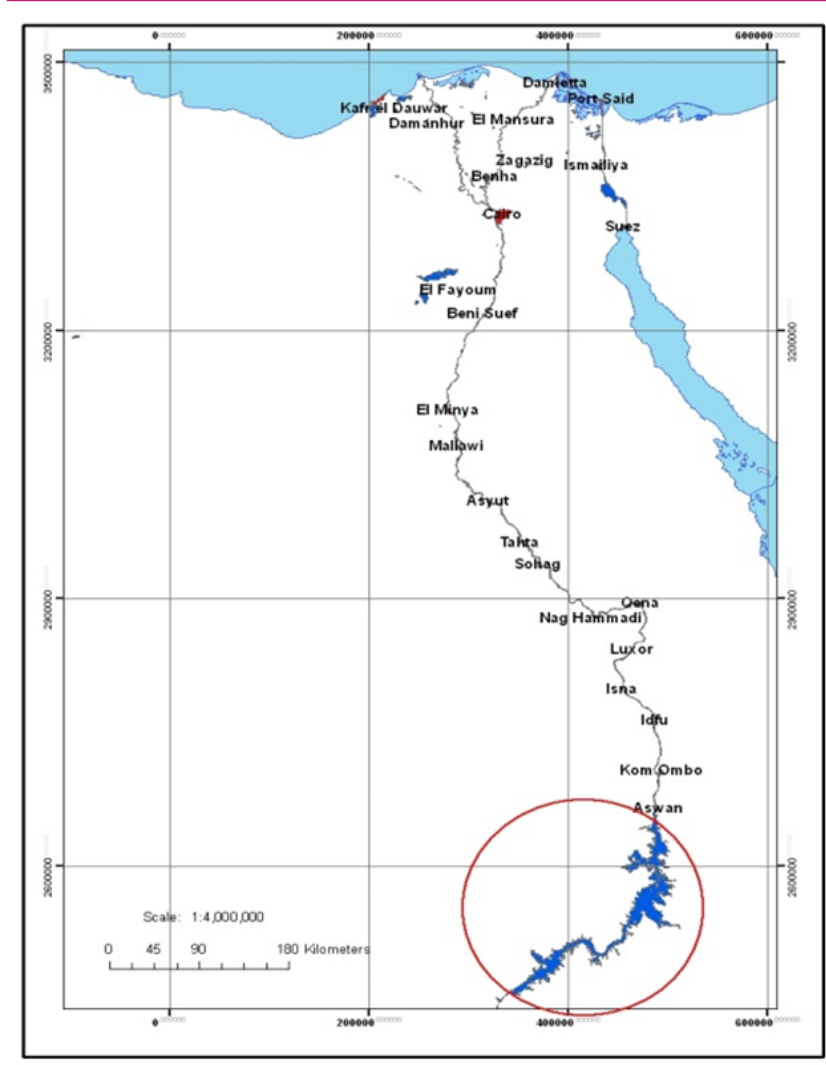

Fig 1. Map of the study lake

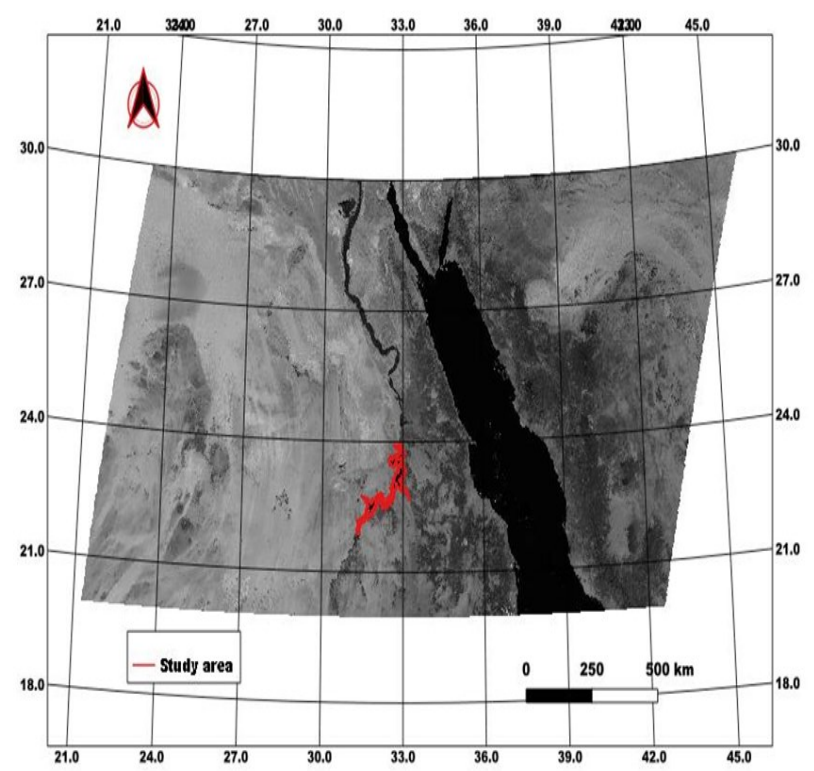

Fig. 2. Map of the mosiked MODIS images acquired on the $29^{\text {th }}$ of September, 2020 (Band 1)

\section{Sentinel-2 data}

Sentinel-2 (S2) was developed by the European Space Agency (ESA) and provided high spatial, spectral and temporal resolution images of the earth. Sentinel-2 had two launches; Sentinel-2A was launched on $23^{\text {rd }}$ of June 2015 and Sentinel-2B on the $7^{\text {th }}$ of March 2017. Those two satellites are at a mean altitude of $786 \mathrm{~km}$ with a revisit time of 5 days. Each satellite provides a set of 13 spectral bands (Vajsováand Aastrand, 2015 and Segarra et al., 2020). Four Sentinel-2 bands were used in this study. These bands were in the blue, green, red and near-infrared bands range of the electromagnetic spectrum available at $10 \mathrm{~m}$ resolution. Six images covered the study area for each date.

The used Sentinel-2 data were available in Level-1C, which is radiometrically, and geometrically corrected reflectance data. Each Level-1C product is a $100 \mathrm{~km} \mathrm{x}$ $100 \mathrm{~km}$ tile available in Geographic Markup Language JPEG2000 (GMLJP2) format and projected into Universal Transverse Mercator (UTM) and World Geodetic System 1984 (WGS 84) with datum-zone 36 N. The data were imported into QGIS software, which supports the GMLJP2 format and exported as Geotiff (Fig. 3).

The properties of MODIS bands used in this study and the corresponding Sentinel-2 bands are shown in Table 1 (Ackerman et al. 1998 and Tianxianget al. 2017).

For downscaling, MODIS data were acquired on the $9^{\text {th }}$ of November, 2017 and the $29^{\text {th }}$ of September, 2020 while Sentinel-2 data were acquired on the $12^{\text {th }}$ November, 2017 and the $27^{\text {th }}$ of September, 2020. MODIS data were acquired for predicting turbidity on $1^{\text {st }}$ of May, 2009 and the $27^{\text {th }}$ of December, 2013.

\section{Field survey and geographic database development}

The used field data covering the study area were available from $23^{\text {rd }}$ of April to $3^{\text {rd }}$ of May, 2009(Central Unit for Water Quality Monitoring, 2009) and from $22^{\text {nd }}$ to $31^{\text {st }}$ of December, 2013 (Nile Research Institute, 2014). The turbidity measurements were available at depth 0$50 \mathrm{~cm}$. Using the QGIS software, the locations of the field observations were developed into a geographic point database. Fifteen samples were collected in 2009 and thirty-three samples were collected in 2013 (Fig. 4). According to Salem (2011), the studied lake could be

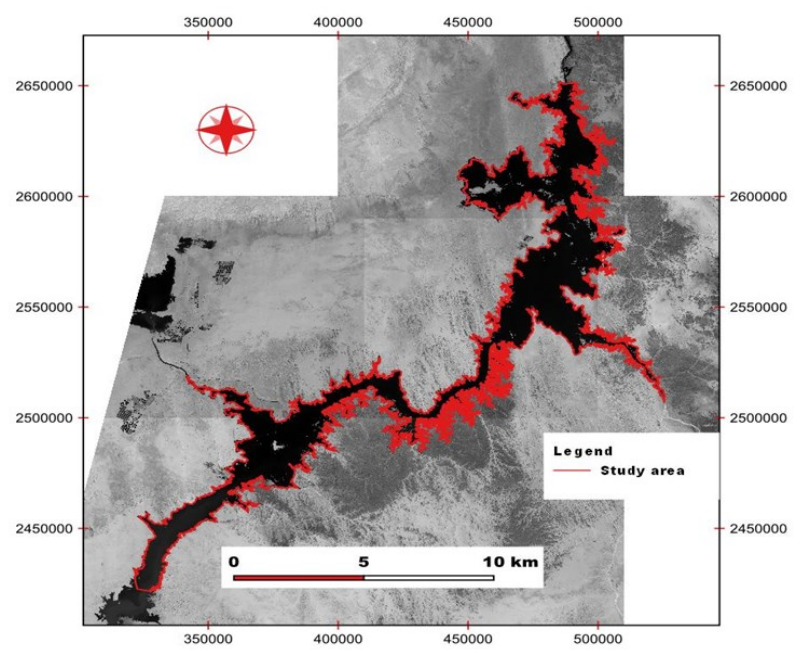

Fig. 3. Map of the mosiked Sentinel-2 images acquired on the $27^{\text {th }}$ of September, 2020 (Band 4) 
divided into the transition zone, extending from Second Cataract to Abu Simble and the lacustrine zone extending from Toushka to the Dam (Fig. 5). The lacustrine zone experiences long local residence times and is characterized by a deeper, lake-like basin with less temporal variability in physical conditions. The transitional zone is characterized by intermediate local residence times, sedimentation and nutrient flushing (Hamre et al., 2017).

\section{Artificial neural networks (ANN)}

In this study, the feed-forward neural network was used when designing the network for both downscaling and turbidity modeling. The information flow in this neural network is unidirectional, i.e. information flow from input to output in one direction with no back loops (Krenkeret al., 2011). For both downscaling and turbidity modeling, the designed neural network utilized $70 \%$ of the samples for training, $15 \%$ for testing and $15 \%$ for validation. The neural network structure was manually alternated using a trial-and-error process until the highest correlation coefficient was achieved (Gummadi, 2013 and

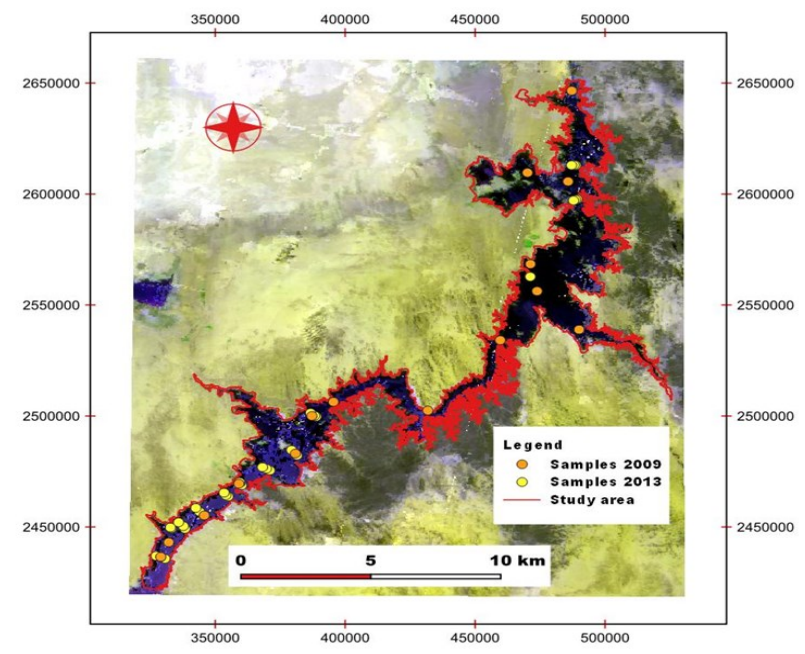

Fig. 4. Map of the sampling locations (Background: MODIS Image (Bands 1,2,3) acquired on April 29, 2009)
Morgan et al., 2017).

\section{RESULTS AND DISCUSSION}

\section{MODIS data downscale}

The data flow diagram for the MODIS data downscale is shown in Fig. 6. To design the neural network for MODIS data downscale, each two matching MODIS and Sentinel-2 bands acquired on each of the selected dates were stacked together into one image. Within these images, MODIS data were resampled into $10 \mathrm{~m}$ spatial resolution. Thereafter, each image was subsetted into the study area. This process resulted in eight images, every four images represented one of the two studied dates and every two images represented one of the studied bands. Nevertheless, the resulting images could not be processed within MATLAB as a whole due to their large size. To enable the processing of these images into MATLAB the images were further subsetted using the Virtual Dataset (VRT) option of QGIS into tiles of 1000 columns $x$ 1000rows.

Furthermore, selected tiles covering all the visual differ-

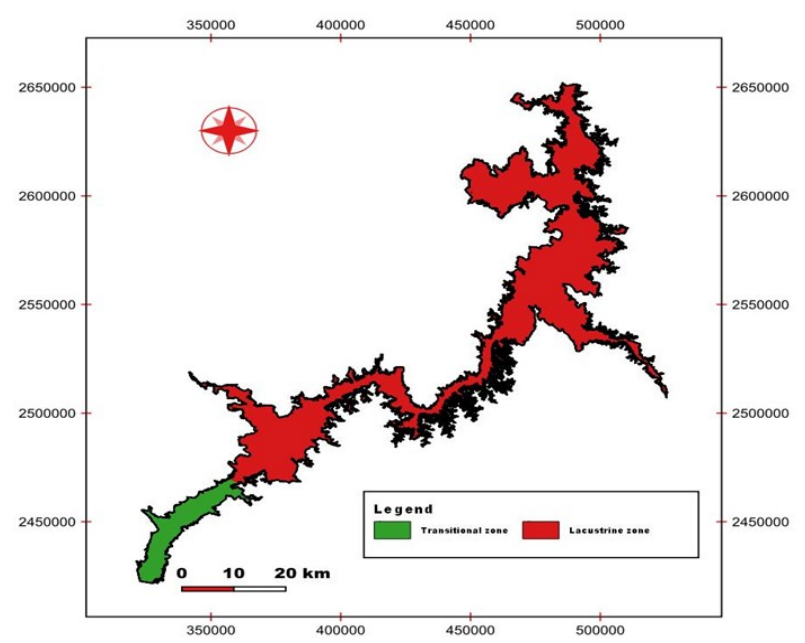

Fig. 5. Map of the different zones of lake Nasser

Table 1. Characteristics of the used MODIS and Sentinel-2 bands

\begin{tabular}{|c|c|c|c|c|c|}
\hline \multirow{4}{*}{ MODIS } & Band No & 1 & 2 & 3 & 4 \\
\hline & Band code & BM1 & BM2 & BM3 & BM4 \\
\hline & Pixel size & 250 & 250 & 500 & 500 \\
\hline & Central wavelength(nm) & 659 & 865 & 470 & 555 \\
\hline \multirow{4}{*}{ Sentinel-2 } & Band No & 4 & 8 & 2 & 3 \\
\hline & Band code & BS4 & BS8 & BS2 & BS3 \\
\hline & Pixel size & 10 & 10 & 10 & 10 \\
\hline & Central wavelength(nm) & 665 & 842 & 490 & 560 \\
\hline
\end{tabular}




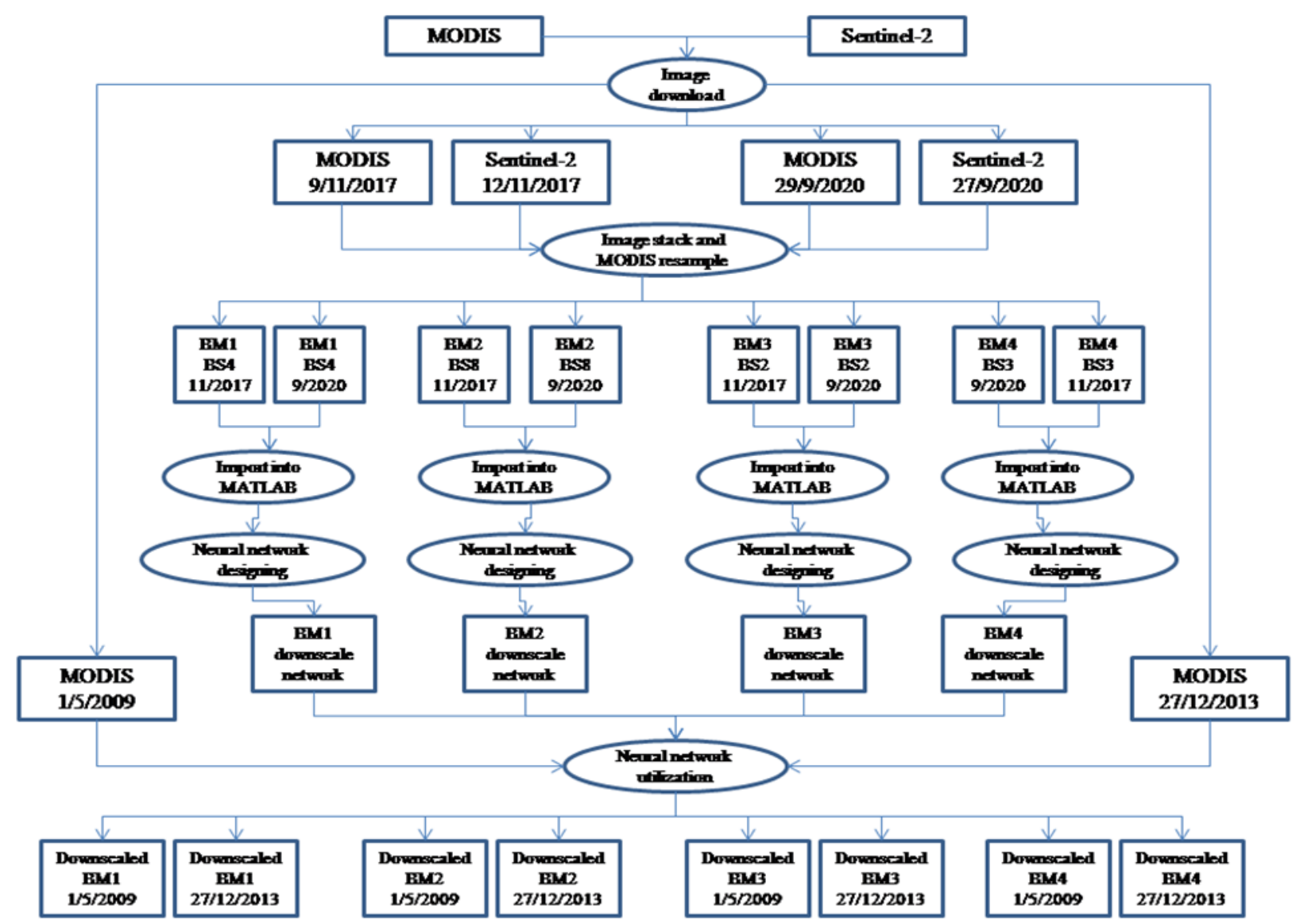

Fig. 6. Data flow diagram of the MODIS data downscale

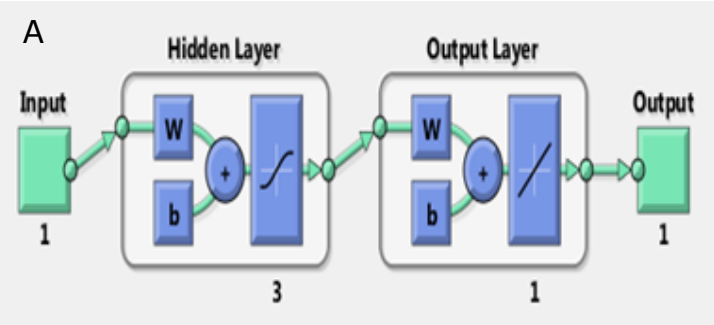

Fig. 7. Architecture of the downscale neural networks

ences were selected. Thereafter, these tiff tiles were imported into MATLAB and merged into a single file for each band. The total count of pixels used reached $800 \mathrm{~K}$ pixels for each band, which were subsequently used to build the neural network using MATLAB's Neural Network Toolbox. The neural network structure was manually alternated using a trial-and-error process until the best performance expressed as coefficient of correlation, $r$, was achieved. The designed network included one node input layer representing MODIS band and one output layer with one node representing the estimated downscaled MODIS data and a hidden layer with 3 nodes for downscaling MODIS bands 1, 2 and 3 (Fig. 7A) while MODIS band 4 included a hidden layer with 10 nodes (Fig. 7B).

When designing these networks, the highest $r$ was between BM3 and BS2 ( $r=0.83)$ followed by BM2 with

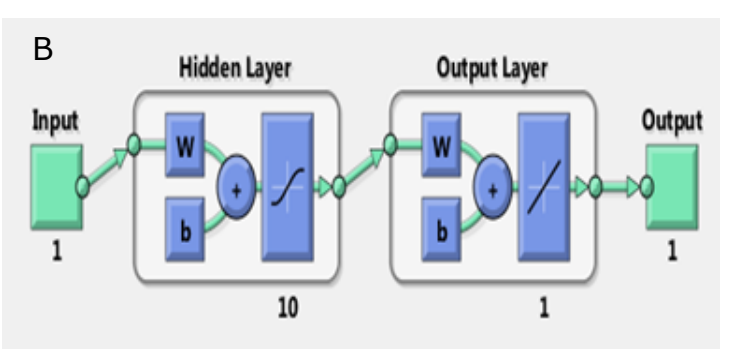

BS8 $(r=0.78)$ then BM1 with BS4 $(r=0.74)$. The least correlation was between BM4 and BS3, reaching $r=0.71$. These designed networks were used to produce downscaled MODIS images acquired on $1^{\text {st }}$ of May, 2009 and $27^{\text {th }}$ of December, 2013. The resulting images were exported from MATLAB in GeoTIFFformat for analysis and visualization in QGIS (Fig. 8a and b).

\section{Lake water turbidity prediction}

\section{Empirical regression model}

The downscaled MODIS image reflectance values corresponding to the turbidity acquired on both $1^{\text {st }}$ of May 2009 and $27^{\text {th }}$ of December2013were extracted and their values were developed into an Excel file for processing. The deigned empirical regression model used the downscaled MODIS reflectance data as independ- 
ent variables and the water quality components (i.e. turbidity) as the dependent variable. Various combinations of MODIS bands were used to design this model. These combinations included the use of single and/or multi bands or bands equations. These equations included the blue and red bandsas recommended by Cox et al. (1998) in equation 1 and the blue, green and red bands defined by Zhuet al. (2004) in Equation 2.

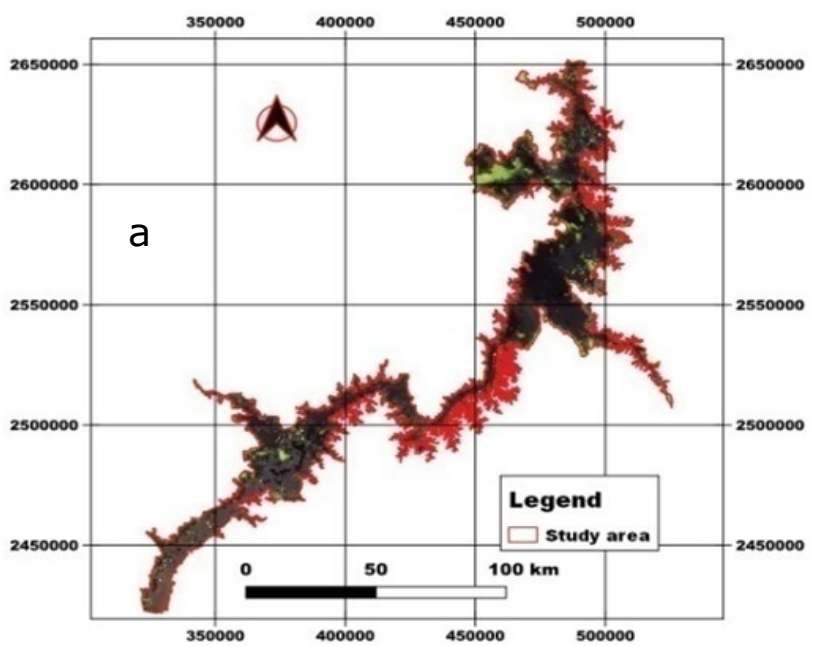

13.8 (MB1/MB3) $)^{4.63}$

MB1+InMB2/InMB3

Equation 1

Equation 2

where $\mathrm{MB} 1, \mathrm{MB} 2$, and $\mathrm{MB} 3$ are blue, green, and red band reflections, respectively.

The regression analysis between the water turbidity and MODIS bands revealed that the highest correlation coefficient was between the near-infrared band(MB4) and turbidity, while the lowest was between turbidity

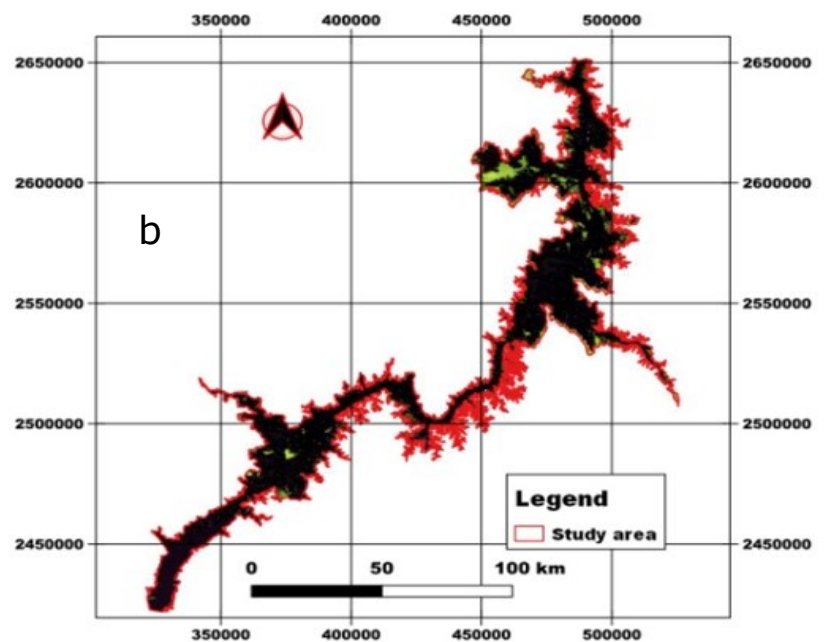

Fig. 8. Map of the downscaled MODIS images (Bands 1,2.3) acquired on the a) $1^{\text {st }}$ of May, 2009 and b) $27^{\text {th }}$ of December, 2013

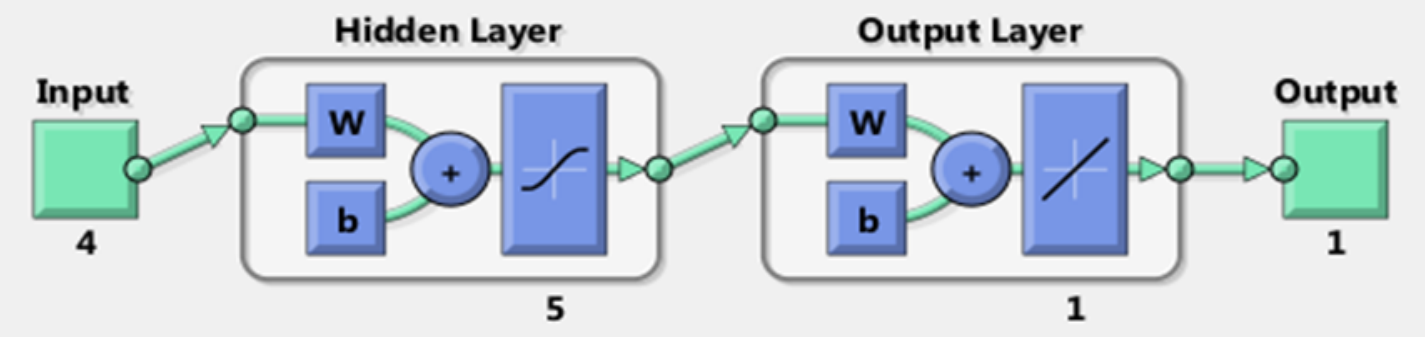

Fig. 9. Architecture of the first neural network for turbidity prediction

Table 2. The results of the correlation between turbidity and MODIS bands

\begin{tabular}{ll}
\hline Band \& Band combination & Correlation coefficient \\
\hline MB1 & 0.42 \\
MB2 & 0.27 \\
MB3 & 0.41 \\
MB4 & 0.46 \\
Eq. 1 & 0.43 \\
Eq. 2 & -0.17 \\
MB1\&MB2\&MB3\&MB4 & 0.68 \\
MB1\&MB3\&MB4 & 0.68 \\
MB1\&MB2\&MB3 & 0.60 \\
MB1\& MB3 & 0.46 \\
\hline
\end{tabular}

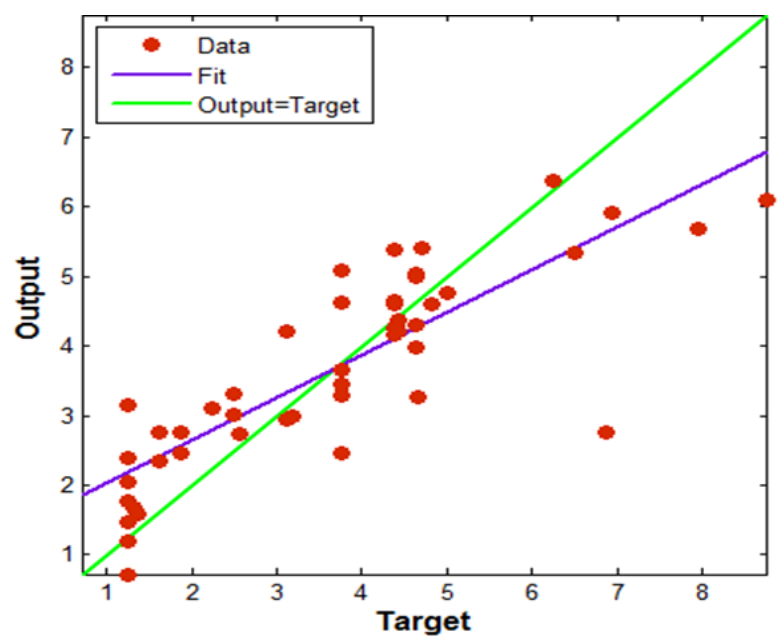

Fig. 10. Performance of the first designed ANN for turbidity prediction 
Table 3. Acreage of the different turbidity classes in Nasser lake

\begin{tabular}{lllll}
\hline \multirow{2}{*}{ Class } & \multicolumn{3}{c}{ May 2009 } & \multicolumn{2}{c}{ December 2013 } \\
\cline { 2 - 5 } & $\mathbf{K m}^{2}$ & \% & . \\
\hline 0-1 NTU & 1320.4 & 18.96 & 780.1 & 11.20 \\
1-5 NTU & 1530.0 & 21.97 & 4378.1 & 62.86 \\
5-10 NTU & 2476.6 & 35.56 & 925.0 & 13.28 \\
10-15 NTU & 713.1 & 10.24 & 274.3 & 3.94 \\
15-20 NTU & 359.2 & 5.16 & 256.6 & 3.68 \\
20-25 NTU & 226.1 & 3.25 & 115.6 & 1.66 \\
25-30 NTU & 63.6 & 0.91 & 9.3 & 0.13 \\
30-35 NTU & 37.8 & 0.54 & 0.0 & 0.00 \\
35-40 NTU & 12.2 & 0.18 & 0.0 & 0.00 \\
Islands & 225.8 & 3.24 & 225.8 & 3.24 \\
Total & 6964.8 & 100.00 & 6964.8 & 100.00 \\
\hline
\end{tabular}

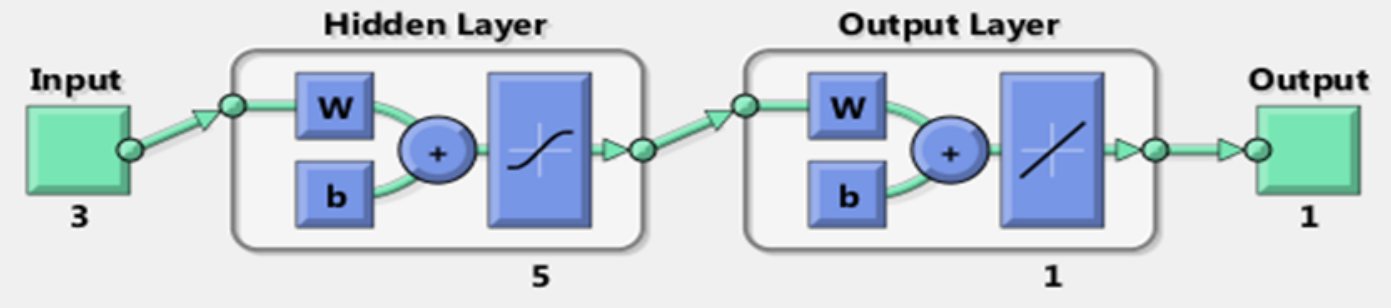

Fig. 11. Architecture of the second neural network for turbidity prediction

and the green band (MB2). The blue and red bands (MB1 and MB3, respectively) had almost similar moderate correlations. Furthermore, utilizing Equation 1 slightly increased the strength of the correlation than each of the first three single bands but still was less than of MR. On the other hand, Equation 2 decreased the correlation more than all the single bands or combi-

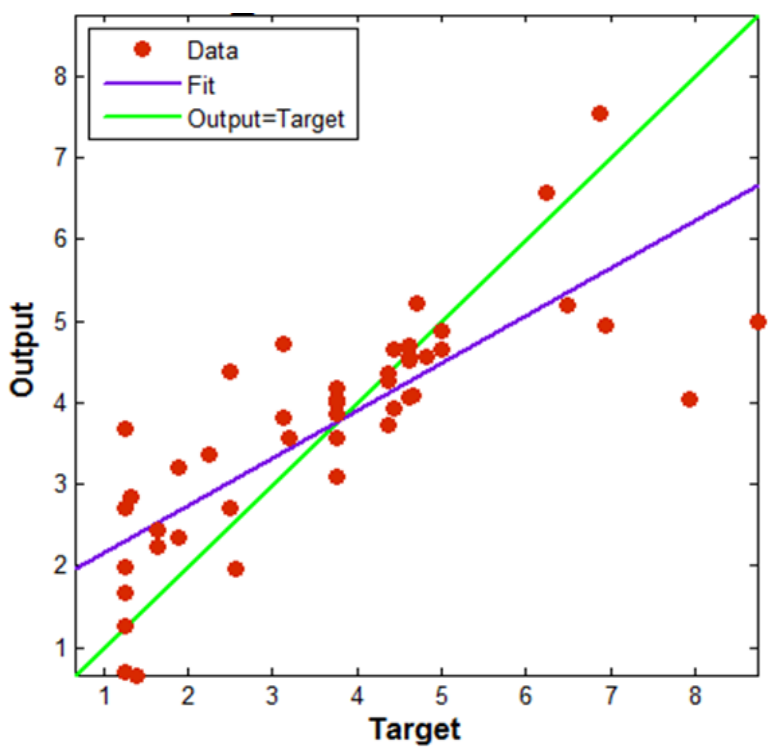

Fig. 12. Performance of the second designed ANN for turbidity prediction nations (Table 2). Furthermore, the correlation coefficient was highest when using the four bands combination of the blue, red and near-infrared bands combination. Therefore, both combinations were used in designing the neural network for turbidity prediction.

\section{Artificial neural networks}

The first designed neural network included one input layer with four nodes indicating the four MODIS bands, a hidden layer with 5 nodes, and one output layer with one node indicating the water turbidity (Fig. 9). The network performance reached $r$ of 0.83 (Fig. 10). The second network included one input layer with three nodes, including the MB1, MB3 and MB4, a hidden layer with 5 nodes, and one output layer with one node indicating the water turbidity (Fig. 11). The network performance reached $r$ of 0.80 (Fig. 12).

Based on these results, the first designed network was used for predicting the water turbidity in Lake Nasser. The images were subsetted to the study area using a shapefile of the lake and its Khores area. As with processing the downscaling of the images, the whole images could not be processed within MATLAB and therefore were subsetted into tiles of 1000 columns $x$ 1000 rows. These tiff tiles were imported into MATLAB and processed using the first designed neural network. The resulting processed images of water turbidity were 


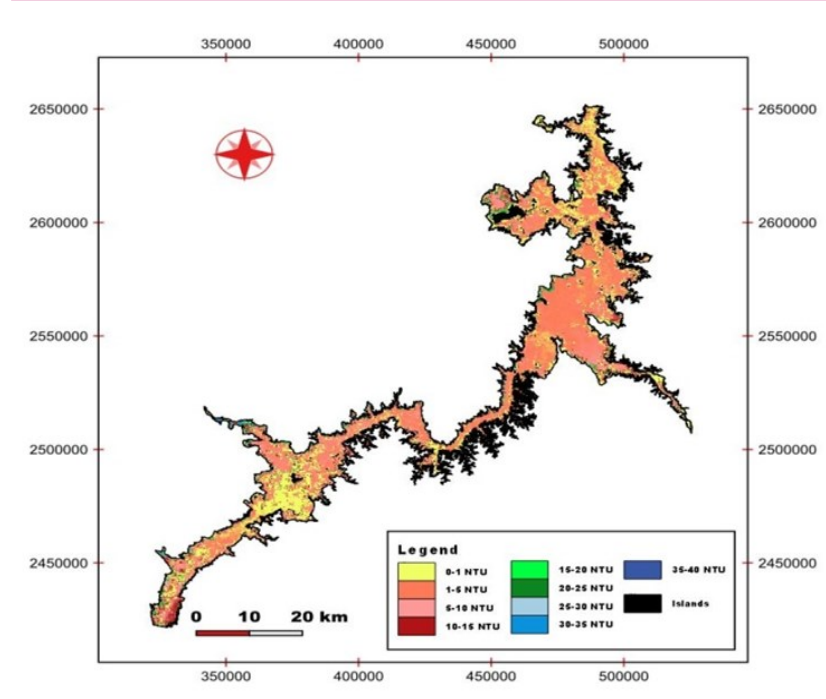

Fig. 13. Map of Lake Nasser turbidity acquired on $1^{\text {st }}$ of May, 2009

thereafter imported into QGIS and merged into one image for each date. Later on, the islands were masked from the resulting images. Thereafter, the images were classified according to the turbidity within each image of 2009 and 2013 (Fig. 13 and 14, respectively).

The measurements were taken in early May 2009 and at the end of December 2013. In other words, it was taken two months before the flood season in 2009 and one month after the flood in 2013 . The turbidity range in May 2009 was higher than in December 2013. While the highest turbidity value reached 36.9 NTU in May 2009, it only reached 28.2 NTU in December 2013. Furthermore, in December 2013, the turbidity below 5 NTU represented $74.06 \%$ of the studied lake while it only $40.93 \%$ of the lake in May 2009 (Table 3). As seen in the images, in both dates, the turbidity was higher in the transitional zone (located in the southern part of the lake) than in the lacustrine zone. Similar results were obtained by Salem (2011) and were explained by the longer local residence times in the lacustrine compared to the transitional zone in Lake Nasser. Moreover, the results of our study revealed that the turbidity in most of Lake Nasser was less than 10 NTU, especially in the lacustrine zone. Furthermore, most of the Khores and lake shoreline areas and surrounding islands were characterized by high turbidity (more than $20 \mathrm{NTU}$ ) on both dates.

\section{Conclusion}

Lake Nasser represents Egypt's freshwater reservoir and it is vital to monitor its characteristics, especially turbidity. MODIS images represent a free source of information that could help fulfil that task. It has been one of the rarely continuous sources of remote sensing data available since 1999. Nevertheless, it is

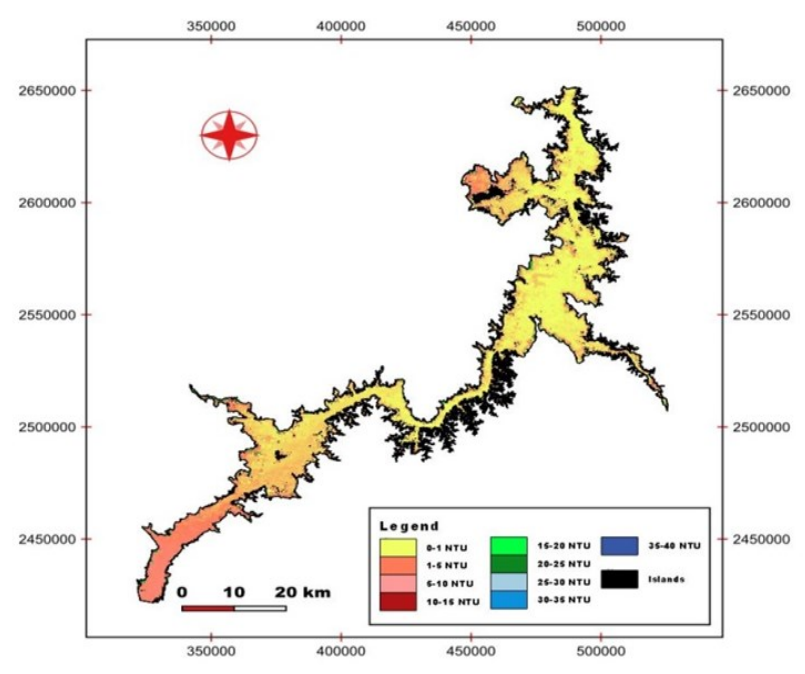

Fig. 14. Map of Lake Nasser turbidity acquired on $27^{\text {th }}$ of December, 2013

constrained by its low spatial resolution that limits its use. The data could be downscaled into a highresolution image such as Sentinel-2 to overcome the low resolution of MODIS images. The present work developed a downscale method utilizing neural networks applied to the first four MODIS bands to reach a resolution of $10 \mathrm{~m}$. This approach reached an accuracy represented as the correlation coefficient of more than 0.70 . Furthermore, in this research, it was possible to demonstrate the use of the downscaled image archive to produce turbidity maps of the lake using neural networks approach as well at dates where no Sentinel-2 data were available. The estimation accuracy of turbidity expressed as a correlation coefficient reached 0.83 . Among the obvious results in this research was that turbidity in most of the mainstream in Nasser Lake was less than 10 NTU. Furthermore, most of the Khores and shoreline areas and surrounding islands were characterized by high turbidity of more than 20 NTU. The developed downscale and turbidity neural network models could be used to predict Lake Nasser water turbidity using the historical and present MODIS data and, therefore, to monitor the changes of the lake over time at a spatial resolution of $10 \mathrm{~m}$. The approach provides a low cost continuous and accurate monitoring data of the lake. Moreover, this approach could be tried to other water quality parameters of the lake. This research recommends further scientific work to be continued in integrating the neural network approach with satellite images processors and GIS to reach more accurate results of the environmental phenomena like water quality in large water bodies such as lakes.

\section{Conflict of interest}

The authors declare that they have no conflict of interest. 
Makar, R. S. and Faisal, M. / J. Appl. \& Nat. Sci. 13(4), 1452 - 1461 (2021)

\section{REFERENCES}

1. AbdEllah, R.G. (2020). Water resources in Egypt and their challenges, Lake Nasser case study. Egyptian Journal of Aquatic Research, 46(1), 1-12. https://doi.org/10.1016/ j.ejar.2020.03.001

2. AbdEllah, R.G. \& El-Geziry, T., (2016). Bathymetric study of some khors in Lake Nasser, Egypt. Lakes, Reservoir and ponds, 10(2), 139-158.

3. Abdullah, H. S. (2010). Water quality assessment for Dokan lake using landsat 8 OLI Satellite images. MSc Thesis submitted to the Faculty of Engineering Irrigation, University of Sulaimani, The Republic of Iraq.

4. Ackerman, S., Strabala, K. I., Menzel, W. P., Frey, R., Moeller, C. C. and Gumley, L. E. (1998). Discriminating clear-sky from cloud with MODIS. J. Geophys. Res., 103, 141-157.

5. Atkinson, P. M. (2013). Downscaling in remote sensing. International Journal of Applied Earth Observation and Geoinformation, 22, 106-114. https://doi.org/10.1016/ j.jag.2012.04.012.

6. Avdan, Z. Y., Kaplan, G., Goncu, S. \&Avdan, U. (2019). Monitoring the water quality of small water bodies using high-resolution remote sensing data. ISPRS International Journal of Geo-Information, 8(12),553-564. https:// doi.org/10.3390/ijgi8120553

7. Blix, K.; Pálffy, K.; Tóth, V. R. \& Eltoft, T. (2018). Remote Sensing of Water Quality Parameters over Lake Balaton by Using Sentinel-3 OLCI.Water, 10(10), 1428-1447. https://doi.org/10.3390/w10101428.

8. Bresciani, M., Giardino, C., Stroppiana, D., Dessena, M., Buscarinu, P., Cabras, L., Schenk, K., Heege, T., Bernet, H., Bazdanis G. \&Tzimas, A. (2019). Monitoring water Quality in two dammed reservoirs from multispectral satellite sata. European Journal of Remote Sensing, 52(4),113122.https://doi.org/10.1080/22797254.2019.16 86956

9. Canziani, G., Ferrati, R., Marinelli, C.\&Dukatz, F. (2008). Artificial neural networks and remote sensing in the analysis of the highly variable Pampean Shallow Lakes. Mathematical Biosciences and Engineering, 5(4), 691-711. https://doi.org/10.3934/mbe.2008.5.691

10. Central Unit for Water Quality Monitoring (2009). A Report on Water Quality Survey of Lake Nasser at its Identified Cross- sectional Areas, Central Unit for Water Quality Monitoring, Ministry of Water Resources and Irrigation, Egypt.

11. Cox, R. M. Jr., Forsythe, R. D., Vaughan, G. E., \& Olmsted, L. L. (1998) Assessing water quality in catawba river reservoirs using Landsat thematic mapper satellite data. Lake and Reservoir Management, 14(4), 405-416. https://doi.org/10.1080/07438149809354347.

12. Cui, J., Zhang, X. \& Luo, M. (2018). Combining Linear Pixel Unmixing and STARFM for Spatiotemporal Fusion of Gaofen-1 Wide Field of View Imagery and MODIS Imagery. Remote Sensing, 10(7),1047-1065.https://doi.org/10.33 90/rs10071047.

13. Erzin, Y., Rao, B.H., Patel, A., Gumaste, S.D. \& Singh, D.N. (2010). Artificial neural network models for predicting electrical resistivity of soils from their thermal resistivity. International Journal of Thermal Sciences, 49(1),118130.https://doi.org/10.1016/j.ijthermalsci.20 09.06.008.

14. Flores-Anderson, A. I., Griffin R., Dix M., Romero-Oliva C.
S., Ochaeta G., Skinner-Alvarado J., Ramirez M. M. V., Hernandez B., Cherrington E., Page B., Barreno F. (2020). Hyperspectral Satellite Remote Sensing of Water Quality in Lake Atitlán, Guatemala. Frontiers in Environmental Science, 8(Article 7), 1-8. https://doi.org/10.3389/ fenvs.2020.00007.

15. Fu, Y.,Xu, S., Zhang, C. \&Sun, Y. (2018). Spatial Downscaling of MODIS Chlorophyll-a using Landsat 8 Images for Complex Coastal Water Monitoring.Estuarine, Coastal and Shelf Science, 209,149-159.https:// doi.org/10.1016/j.ecss.2018.05.031.

16. Guan, X. (2009). Monitoring Lake submitted to Simcoe Water Quality Using Landsat TM Images.MScsubmitted to the University of Waterloo, Waterloo, Ontario, Canada.

17. Gummadi, J. A. (2013). Comparison of Various Interpolation Techniques for Modeling and Estimation of Radon Concentrations in Ohio. MSc submitted to the University of Toledo, TheUnited States of America.

18. Hamre, K.D. Gerling, A.B., Munger, Z.W., Doubek, J.P., McClure, R.P., Cottingham, K.L. \& Carey, C.C. (2017). Spatial Variation in Dinoflagellate Recruitment along a Reservoir Ecosystem Continuum. Journal of Plankton Research, 39(4), 715-728. https://doi.org/10.1093/plankt/ fbx004.

19. Krenker, A., Bester, J. \& Kos, A. (2011). Introduction to the Artificial Neural Networks, Artificial Neural Networks Methodological Advances and Biomedical Applications, Kenji Suzuki (Ed.), InTech, 1-18. ISBN: 978953-307-243-2,.http://www.intechopen.com/books/artificial -neural-networks-methodological-advances-andbiomedical-applications/introduction-to-the-artificial-neural -networks

20. Kumar, N., Yamaç, S. Murugan, A. (2015). Applications of Remote Sensing and GIS in Natural Resource Management. The Andaman Science Association, 20, 1-6.

21. Li, W., Ni, L., Li, Z., Duan, S. \& Wu, H. (2019). Evaluation of machine learning algorithms in spatial downscaling of MODIS land surface temperature. IEEE Journal of Selected Topics in Applied Earth Observations and Remote Sensing, 12, 7, 2299-2307.

22. Liu, W., Liu, Y., Mannaerts, C.M. \&Wu, G. (2007). Monitoring variation of water turbidity and related environmental factors in Poyang lake National nature reserve, China. Proc. Society of Photo-Optical Instrumentation Engineers (SPIE) 6754, Geoinformatics 2007: Geospatial Information Technology and Applications, 67541H. https:// doi.org/10.1117/12.764879.

23. McCullough, I.M., Loftin, C.S., \& Sader, A.S. (2012). HighFrequency Remote Monitoring of Large Lakes with MODIS $500 \mathrm{~m}$ Imagery. Remote Sensing of Environment, 124,234-241. https://doi.org/10.1016/j.rse.2012.05.018.

24. Mohebzadeh, H. \& Lee, T. (2020). Spatial downscaling of MODIS chlorophyll-a with machine learning techniques over the west coast of the Yellow Sea in South Korea. Journal of Oceanography, 77,103-122. https:// doi.org/10.1007/s10872-020-00562-6.

25. Mohsen, A., Elshemy, M. \&Zeidan, B. (2021). Water quality monitoring of lake Burullus (Egypt) using landsat satellite imageries. Environmental Science and Pollution Research, 28, 15687-15700. https://doi.org/10.1007/s11356020-11765-1.

26. Moreno-Madrinan, M.J.; Al-Hamdan, M.Z.; Rickman, D.L.; 
Muller-Karger, F.E. (2010). Using the Surface Reflectance MODIS Terra Product to Estimate Turbidity in Tampa Bay, Florida. Remote Sensing,2(12), 2713-2728. https:// doi.org/10.3390/rs2122713.

27. Morgan, R.S., Abd El-Hady, M., Rahim, I.S., Silva, J., \& Ribeiro, S. (2017). Evaluation of Various Interpolation Techniques for Estimation of Selected Soil Properties. International Journal of GEOMATE, 13 (38), 23-30.Nile Research Institute (NRI) (2014). A Report on A Scientific Trip of Lake Nasser (from 19th December 2013 to 2nd January 2014), Nile Research Institute of the National Water Research center in collaboration with High Aswan Dam Authority of the Ministry of Water Resources and Irrigation, Egypt.

28. Nomura, R. \& Oki, K. (2021). Downscaling of MODIS NDVI by Using a Convolutional Neural Network-Based Model with Higher Resolution SAR Data. Remote Sensing, 13(4), 732-751. http://dx.doi.org/10.3390/rs13040732.

29. Salem, T. A. (2011). Variation of Water Quality and Phytoplankton along Different Zones of Aswan High Dam Reservoir. Egypt J. Aquat. Biol. \& Fish., 15(2), 87 - 104. http:// dx.doi.org/10.21608/ejabf.2011.2091.

30. Santi, E. (2010). An Application of the SFIM Technique to Enhance the Spatial Resolution of Spaceborne Microwave Radiometers. International Journal of Remote Sensing, 31 (9), 2419-2428. https://doi.org/10.1080/014311609 03005725.

31. Segarra, J.; Buchaillot, M.L.; Araus, J. L. \& Kefauver, S. C. (2020). Remote Sensing for Precision Agriculture: Sentinel-2 Improved Features and Applications. Agronomy, 10 (5), 641-658. https://doi.org/10.3390/agronomy10050641.

32. Senanayakea, I.P. ,Yeoa I., Willgoosea, G. R., Hancockb, G. R. \&Bretregera, D. (2019). Using an artificial neural network to enhance the spatial resolution of satellite soil moisture products based on soil thermal inertia. 23rd International Congress on Modelling and Simulation, Canberra, ACT, Australia, 1-6 December ,2019.

33. Tianxiang, Z., Jinya, S., Cunjia, L., Wen-Hua, C., Hui, L.
\&Guohai, L. (2017). Band selection in sentinel-2 satellite for agriculture applications. Proceedings of the 23rd International Conference on Automation \& Computing, University of Huddersfield, Huddersfield, UK, 7-8 September, 2017.

34. Toming, K., Kutser, T., Laas, A., Sepp, M., Paavel, B. \& Nõges, T (2016). First experiences in mapping lake water quality parameters with Sentinel-2 MSI imagery. Remote Sensing, 8(8),640-653. https://doi.org/10.3390/rs8080640.

35. Vajsová, B.\& Aastrand, P. J. (2015). New Sensors Benchmark Report on Sentinel -2A. JRC Technical Reports, Publications Office of the European Union. EUR 27674 EN.

36. Vermote, E. (2015a). MOD09A1 MODIS/Terra Surface Reflectance 8-Day L3 Global 500m SIN Grid V006 [Data set]. NASA EOSDIS Land Processes DAAC. https:// doi.org/10.5067/MODIS/MOD09A1.006.

37. Vermote, E. (2015b). MOD09Q1 MODIS/Terra Surface Reflectance 8-Day L3 Global 250m SIN Grid V006 [Data set]. NASA EOSDIS Land Processes DAAC. https:// doi.org/10.5067/MODIS/MOD09Q1.006

38. Wang, Q., Shi, W., Li, Z. \& Atkinson, P. (2016). Fusion of Sentinel-2 images. Remote Sensing of Environment, 187, 241-252. https://doi.org/10.1016/j.rse.2016.10.030.

39. Wu, M., Zhang, W., Wang, X. \&Luo, D. (2009). Application of MODIS Satellite data in monitoring water quality parameters of Chaohu Lake in China. Environmental Monitoring and Assessment, 148, 255-264. https:// doi.org/10.1007/s10661-008-0156-2.

40. Yoo, C., Im, J., Park, S., \& Cho, D. (2020). Spatial Downscaling of MODIS Land surface temperature: Recent research trends, challenges, and future directions. Korean Journal of Remote Sensing, 36(4), 609-626. https:// doi.org/10.7780/kjrs.2020.36.4.9

41. Zhu, L., Wang, S., Zhou, Y., Yan, F. \& Zhou, W. (2004). Water quality monitoring in Taihu Lake using MODIS image data. IEEE International Geoscience and Remote Sensing Symposium, 2004 (IGARSS 2004), 4, 23142317.https://doi.org/10.1109/IGARSS.2004.1369749. 